\title{
ANTI-SEISMIC PRESIDIA IN THE HISTORICAL BUILDING OF L'AQUILA: THE ROLE OF THE WOODEN ELEMENTS
}

\author{
ALESSANDRA TOSONE \& ALESSANDRA BELLICOSO \\ Dipartimento di Ingegneria Civile Edile-Architettura e Ambientale, Università dell' Aquila, Italy.
}

\begin{abstract}
The earthquake of 2009 has brought to light different anti-seismic presidia implemented over the centuries, in the aftermath of repeated earthquakes occurred in the city of L'Aquila, which represent the result of a knowledge and a constructive culture linked to a direct observation of the damage, the intuitive interpretation of the seismic response and the possible countermeasures experimentation.

An important role is attributed to the wooden elements that have different functions and are used in the context of standard and palace building.

The integration of the wooden elements can become a real system and be extended to the entire building unit, as in the case of the adoption of the 'hut' system (sistema baraccato). Alternatively, it can be used only for single and specific building elements, such as the use of 'wooden roots' (radiciamenti lignei) in the walls and vaults or wooden elements used for the construction systems of the roofing.

This article aims to contribute to the knowledge of these anti-seismic systems, framed within a broader constructive culture linked to the pre-modern building.

Keywords: anti-seismic presidia, construction techniques historic building, local seismic culture.
\end{abstract}

\section{INTRODUCTION}

The damage of the last earthquake that struck L'Aquila in 2009 and the subsequent reconstruction work have shown, inside the historic building network, the widespread use of wooden elements as anti-seismic presidia, applied and tested over the centuries following repeated telluric events, according to individual or collective structure needs.

This is the case of the wooden roots inside the masonry embedded with the function of wooden chains, improvement of the scarves near the masonry and cantonal hammers (martelli murari e cantonali) or correction of irregular masonry. Similar wooden elements can be found into the structure of the masonry vaults with the role of countering the thrust and improve the box-like behaviour of the walls.

The use of additional wooden elements is the key feature of the design concepts of the roofing. In other cases, the adoption of the 'hut' system involves the entire constructive unit in new buildings or, on the contrary, part of it in the partial reconstruction activities.

This study aims at understanding whether the anti-seismic measures, linked to the local building culture, represented a field of experimentation and anticipation of the official technical culture expressed in journalism history or if, on the contrary, they have assimilated knowledge from experience and practices already codified. Therefore, the methodology of the study envisaged the analysis of direct sources along with the analysis of indirect sources present in the historical treatises and manuals and the first anti-seismic norms and regulations implemented after the major earthquakes of the 17th and 18th centuries.

Indeed, the methodological approach has allowed defining, in terms of time, the comparison between the implementation of different measures involving the use of wooden elements and their presence in the technical publications in order to evaluate the experimental nature and, in analytical terms, the consideration of similarities rather than of differences compared to the codified practices. 


\section{LOCAL SEISMIC CULTURE AND THE WOODEN ROOTS}

The different processes of reconstruction involving the city of L'Aquila hit by several earthquakes, among the most relevant in terms of intensity and level of damage, those occurred in $1315,1349,1461$ and 1703, are often connected to significant realignment of the urban structure. With the transformation of the basic building types and the redefinition of the architecture of the fronts, it implies a progressive alteration of the building rules for the construction of walls and a wise use of technical controls to secure a construction consistent with the rules of art and to reduce the possible critical conditions related to recurrent earthquakes.

The rationality and regularity of the medieval urban structure, organized on regular parcels of $4 \times 7.5$ rods, with the presence of buildings in the $50 \%$ of the area, and the building skill of masonry characterized by the 'apparecchio aquilano' (Gavini [1]) attributable to the Angevin construction site, is lost in the urgency of the city's reconstruction after several earthquakes. Starting from the 15th century, a process of transformation of the urban structure begins and leads to an extension of the built environment, achieved through the re-appropriation of basic building types and the progressive occupation of gardens, along with an increase in the number of floors.

These particular circumstances led to an improved focus on rules and precautions that, based on the recurring damage, are used in a preventive manner both in the activity of rebuilding from scratch and for the restoration of damaged buildings. In this way, they can be effectively treated as real pre-modern anti-seismic measures.

By looking at the historical building structure, it is possible to detect a widespread ability to put in place a series of constructive solutions aimed at increasing the building resistance to the earthquake. They represent the feature of a complex and articulated 'local seismic culture' (Pierotti, Ulivieri [2]). Such culture has been continuously used and tested in a fairly long period of time supporting the 15th- and 18th-century reconstructions, through a building practice based on a profound knowledge of the wall structure and on a perfect creation of the artefacts.

The precepts of art ensure 'stability and durability of the building' also 'where the most frequent natural disasters occur' (Cavalieri San Bertolo [3]) and the description of the building techniques provides anti-seismic indications. All of them are mainly focused on the connection of building elements: 'the frames are to be connected with frames, and they will all be strengthened in the most appropriate manner with nerves and ligaments; so that the sequence of frames, connected together, is able to resist alone, even in case of failure of any other element' (Alberti [4]).

In the peculiar structure of the building fabric of L'Aquila, both from the perspective of the standard building and the palace building, an important role, as 'ligament', is attributable to the presence of wooden roots. According to different criteria and technical procedures, they integrate, primarily in the form of beams, walls and vaulted horizontal elements, or define more specifically the design concepts of 'staked' floors and roofs.

The use of wooden elements in the walls, probably already known in the Middle Ages defensive architecture even in the Abruzzo area, gradually becomes part of building practices as a result of the earthquakes of the mid-15th century.

During the reconstruction period, after the earthquake of 1703, the use of wooden roots was significantly extended to the entire building structure and, with specific improvements, becomes 'a real building methodology, neither sporadic, nor random' (Bramanti [5]). In addition, it was fully recognized by the 19th-century journalism technique: 'In civil buildings there are generally, within the thickness of the walls, hidden oak beams which are placed horizontally in the upper parts of each plan and conveniently joint with iron straps, where 
two following rafters are found one after the other or where the joists are placed in a wall and meet those located in other walls, serve to keep all the walls well concatenated and to partially eliminate the effects of horizontal thrusts' (Curioni [6]).

\subsection{Animated masonry}

L'Aquila's wooden beams walls are placed lengthways and embedded within their thickness with the aim of improving the meshing of the wall. In fact, the lack of well-meshed orthostats, due to a masonry predominantly made of little stone material, had shown a poor resistance. The 'roots' also called 'dead keys' or 'dead beams' are embedded in the masonry as a real armour that, by resorting to the wood's tensile strength, is capable of ensuring higher quality in terms of strength and stability (Fig. 1).

With the addition of retaining elements, the roots act as chains able to link two wall panels in order to counter their estrangement. The wooden chains, placed to the portion of the horizontal structures, also according to inter-floor height, are precisely secured within the thickness of the wall with iron and wood retaining elements, or nailed to the wooden cables; they can also be placed inside out, on the outer face of the wall by means of 'stacking' systems, with wooden or metallic anchor bolts and bolted end-plates.

Wooden beams are also placed outside the wall, near the masonry hammers (martelli murari), embedded in the thickness of the floor and in particular in the space of the abutment of the vaults often incorporated into the system of the steering cables (Fig. 2).

With the aim of ensuring an improvement of the box-like behaviour of the walls compared to a significant longitudinal development of the fronts, they are mainly found in the type of the building.

With the same purpose, the systematic placement of roots in the masonry structure generates spiral reinforcements, placed at different heights in relation to the size of the building and its vertical structure; the wooden beams, properly steamed by simple riveting or 'Jupiter dart-pin' connections, intersect near the angled and end outside the cantonal with metallic anchor bolts studded on the head of the beams and retaining bolted-end-plates, according to different shapes that, in the High Renaissance, are characterized by floral and animal motifs.
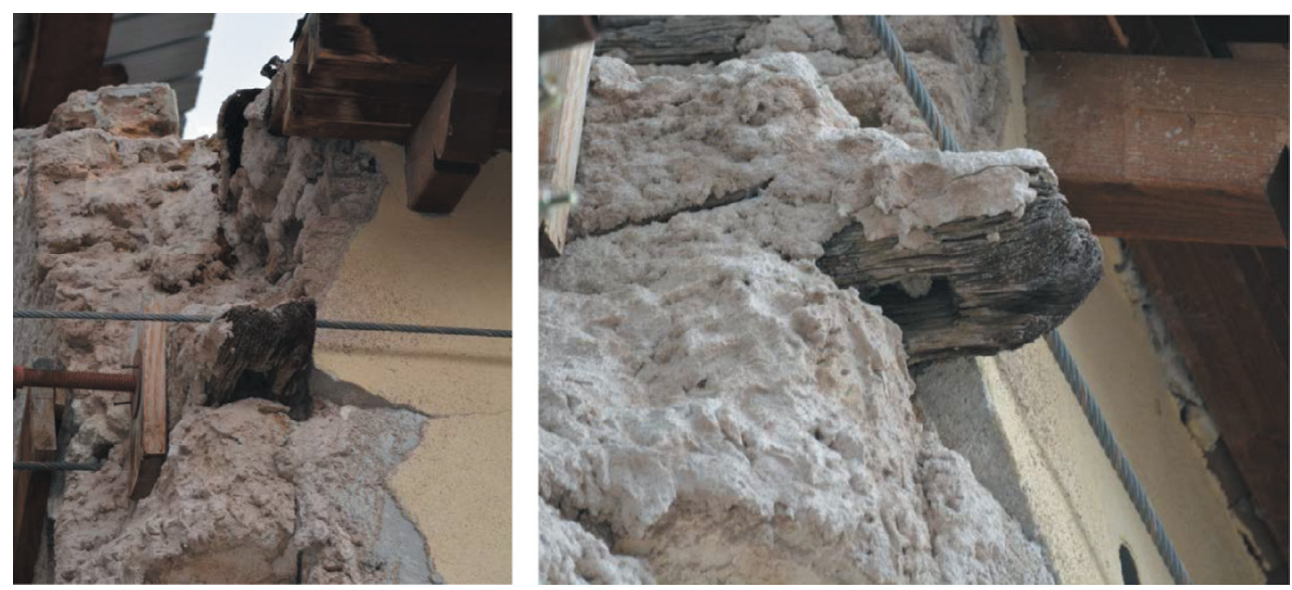

Figure 1: Wooden chains placed inside the wall. Building in Piazza San Domenico. 

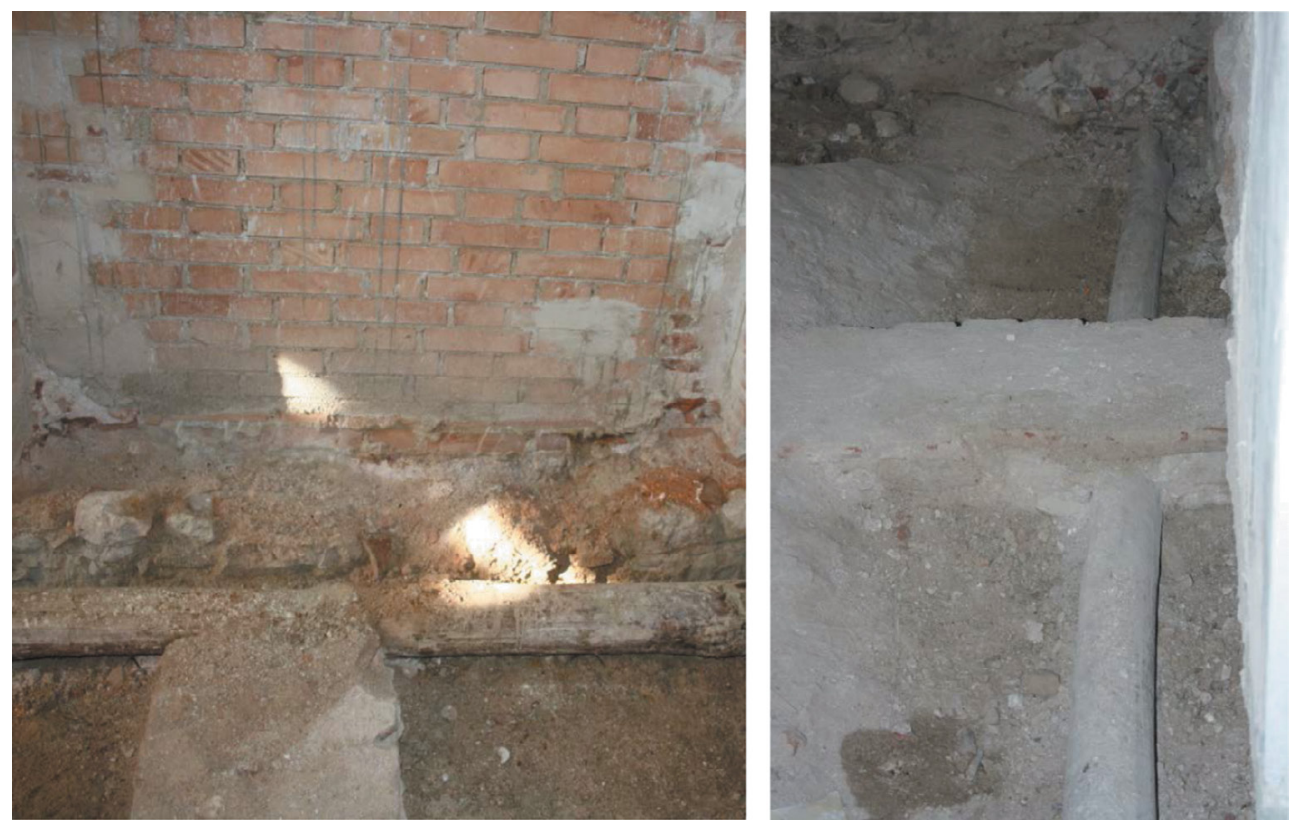

Figure 2: Wooden chains placed outside the wall of Palazzo Zuzi.

\subsection{Thrust-retained vaults}

The wooden roots are also employed in the vaulted systems with different modalities according to their structure and size. They are mainly used in heavy brick vaults: 'reinforcement or counter-thrust keystones of arches vaults (...) placed especially in the arches and also in the vaults, especially when these are characterized by a considerable width and length, serve to counterbalance the effect of the thrust, mostly when the rise is significantly depressed' (Astrua [7]).

In L'Aquila, this approach was mainly used during the construction or reconstruction of the vaults, after the earthquake of 1703, in the palatial architecture intended for large rooms, built with brick course laid on edge according to different types of equipment; in fact it is important to encase the vault in larch and pine board, so that the vaults can be robust and long-lasting' (Pellegrino [8]).

In the case of barrel vaults with longitudinal structure, the wooden beams are placed transversely to the generatrix, partially embedded into the upper part of the element, free or leaning against the steering cables and connected to the exterior wall, thanks to concealed or exposed retention systems. The chain can be integrated with other wooden elements, just like the 'sling chains' described by Valadier [9], or according to more complex structures in which the transverse chains are longitudinally contrasted by rafters where retaining elements, embedded in the abutment, are connected (Fig. 3). Conversely, in the case of 'intersected' vaults (e.g. rib vaults), the roots are placed parallel to the generators and integrated inside the bricks to about a third of the rise. The beams are placed on the four sides of the vault; they intersect and connect near the corner, and then bound to the exterior walls. Mainly on the longest sides of the vault, the beams can be supplemented with other retention wooden elements that reconnect them to the perimeter walls. 

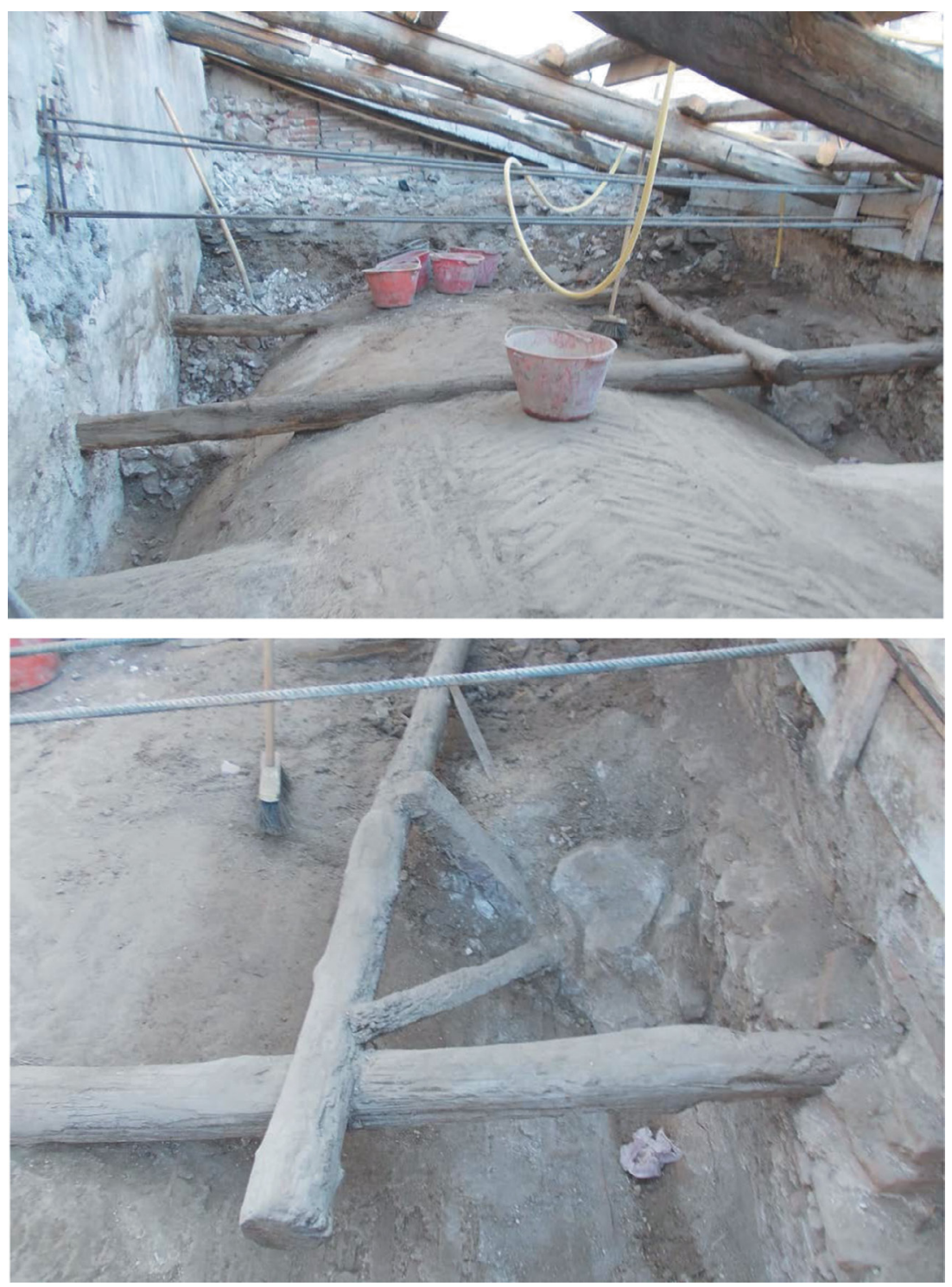

Figure 3: Palazzo Gualtieri. The transverse chains are longitudinally contrasted by rafters where retaining elements, embedded in the abutment, are connected.

In the case of roofing, the system of the wooden chains can become even more complex with beams leaning against the cymatia of the interior walls, horizontally connected with those placed at the top of the vaults. This system can also involve the chains of the trusses when the attic is moderately high.

\subsection{Staked trusses and box-shaped roofs}

Even in the context of smaller building works, the roofing system favours the use of the truss, searching for optimal criteria just inside the good rule of art. The assessment of the effects 
of the earthquake on roofing systems and the development of local anti-seismic culture, lead to the adoption of elements and systems that can eliminate or counter the most common risk associated with extraction of the trusses from the exterior field. Therefore, to increase the retention capacity of the chain in the phase of oscillation of the walls, which is normally only entrusted to the single friction force, the truss construction structure is modified through a different solution of the support knot (Fig. 4).

The chain becomes ligament and, extended beyond the wall thickness, it is equipped with a bollard retaining system, in order to ensure an improved connection between the roofing and wall, synchronizing the oscillation and leading to a better 'behaviour' of the building.

The 'staked' truss is completely embedded in the wall and equipped with a wooden cushion, carved and sometimes moulded, in the support area. It is characterized by a much greater length than that of a normal shelf, 'a piece of rustic beam, and sometimes shelf-shaped at the extremities, which is nailed under another wood, under the beams, to the struts of roofs, inside the frames and in almost all the rebars (...)' (Ragucci [10]).

This damper, also known as 'slide' that is surely intended to protect the head of the truss, comes out and allows the creation of the fixing hole of the wooden stake, and extends inside under the chain so as to increase the surface friction of the retaining mechanism and avoid compromising its support in the event of chain sliding (Fig. 5).

The same construction knot can also be complemented with further wooden element, a tilted beam called 'polsa', which is nailed and paired with the rafter and the cushion while extending itself outside so as to create the warping of the eaves.

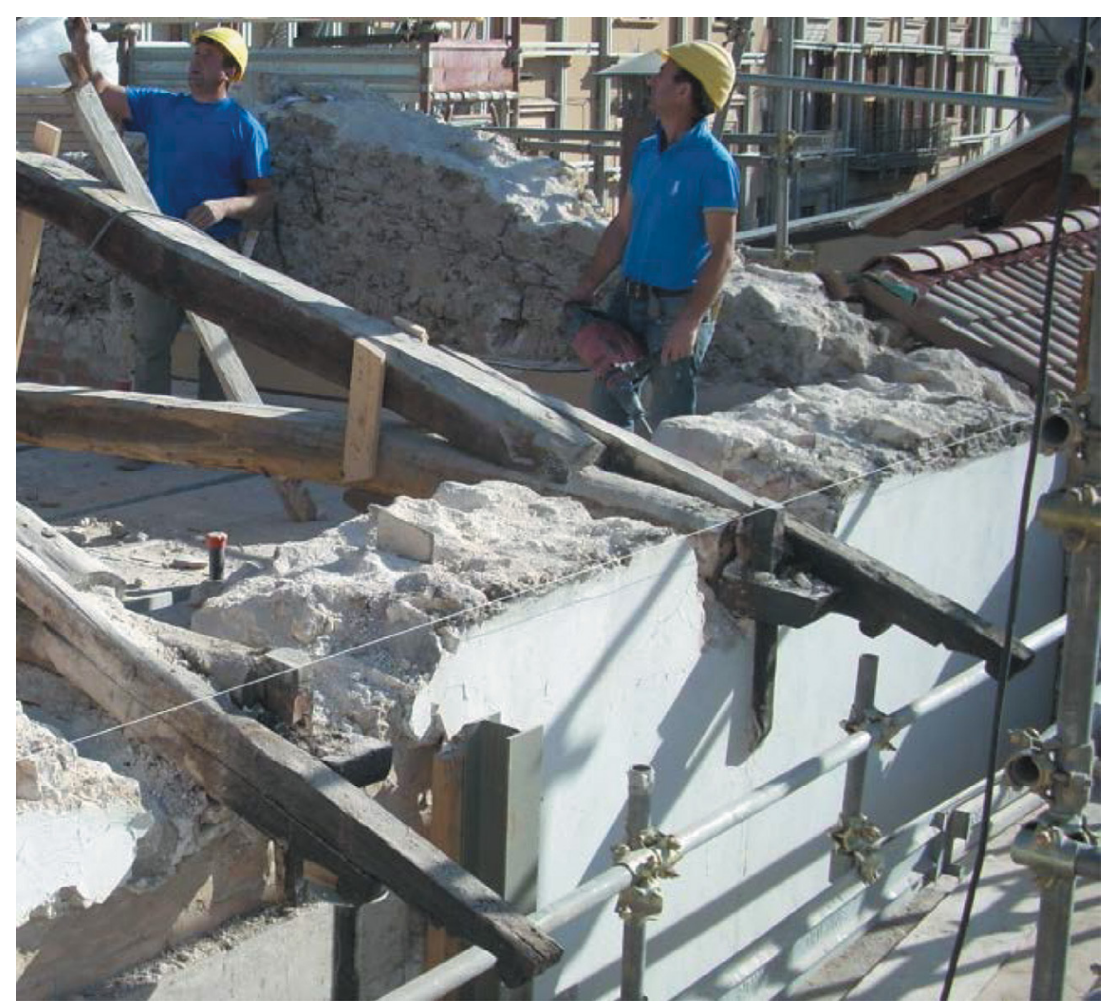

Figure 4: The typical example of the staked trusses applied in Palazzo Farinosi. 

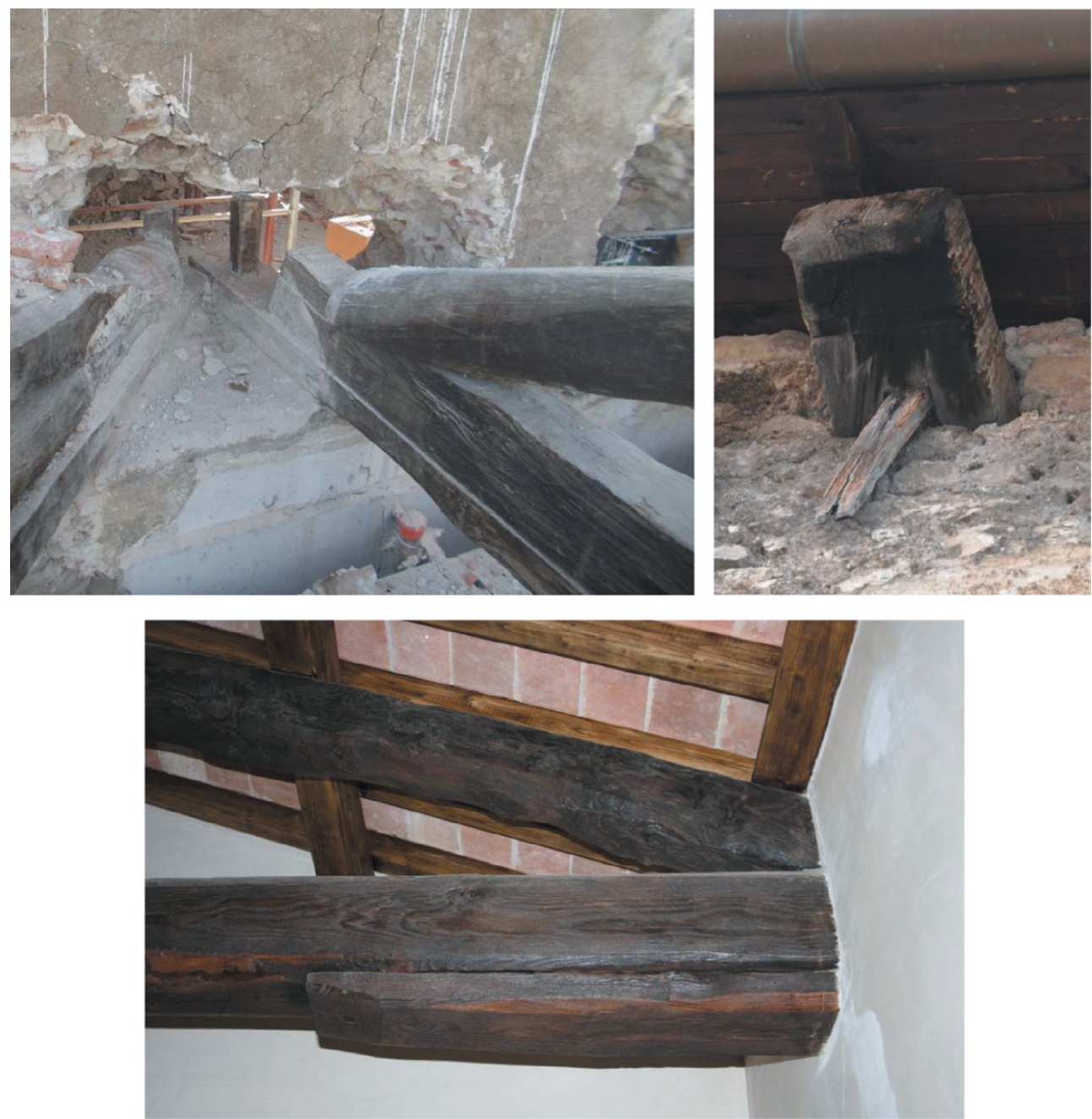

Figure 5: Details of the support knot solution in Palazzo Farinosi.

Another type of solution for the roofing does not change the type of the truss but otherwise resolves its correlation with the masonry. In this case, longitudinal beams are embedded and connected to the summit walls by stakes where the elements of the roof structure are placed and secured in order to create a box-like system. 'A kind of rebar of continuous beams, first staked and then snapped; which tightened with clamps and iron bands, and fit along the thickness of the walls, on which the roof lies. The extremities of the chains, rafters and racks joint and embedded in the box, generate a system that instead of pushing the walls, it evenly press over their whole length' (Ragucci [10]).

\section{SEISMIC CULTURE AND HUT SYSTEM}

The structural type of 'hut' house is one of the oldest and most used systems for the purpose of seismic safety. Usually, it is made of wooden skeleton and a part of light-materials infillings, but also bricks or stones (Barucci [11]), and its alleged origin refers to the 'opus 
craticium' discovered in Pompeii and Herculaneum, where a framework of wooden beams made of uprights and transoms marks modular areas within which a masonry of stone chips and mortar (Ceniccola [12]).

In fact, the use of wood inside the masonry in order to chain and make the structure supportive structure has very ancient origins, already described in the construction of the walls of the city by Vitruvius and by Gaius Julius Caesar for those of the Gallic city built with beams, freestones and soil.

In historical treatises, it is extremely rare to see a section specifically dedicated to the anti-seismic construction, as the 'rule of art' at the base of technical and constructive culture was considered sufficient to make buildings able to withstand earthquakes. During the 18th century, more attention was attached to anti-seismic construction studies and specific writings (Paolini [13]). In 1781, Francesco Militia in his work 'Principi di Architettura Civile' describes a reinforced masonry system with wood and also proposes one of the first wooden anti-seismic home models provided by the manuals (Barucci [11]).

Only after catastrophic earthquakes, the 'hut' system is coded in its many variations even within specific, and not only Italian, regulations.

The Benevento-style hut system is considered as the best and most suitable technique for the reconstruction of Benevento after the 1627 Gargano earthquake, which also involves the Sannio area, although other sources connect the birth of the technique to the reconstruction following the 1688 Sannio earthquake (Ceniccola [12]). 'A timber reinforcing cage, created with the so-called Benevento-style frames, made of many nailed and bolted wooden studs with as many beams, whose resulting meshes were closed and secured with light material; or better with a wicker or cane woven, secured to the frame by thin chestnut slats and covered with mortar or a well smoothed rough coat' described by Masciari-Genovese [14] in 1915 as the first stage of anti-seismic architecture.

Fabrizio [15], in 1933 refers to it as 'a chestnut timber skeleton with rectangular meshes, with squared studs, directly planted in the ground, or in a base masonry. Both sides of the frames were complemented with wicker walls: common reed (Phragmites australis), suitably plastered slats. Everything was plastered after application of mortar rough coat or well coated clay'. However, in the Sannio area both variants with studs and transoms with masonry infill, and variants with studs, transoms and diagonals arranged according to St. Andrew's cross model with infill masonry made of an uneven texture of rows of bricks and blocks of hewn limestone (Ceniccola [12]).

Another system provided for by an anti-seismic regulation is the 'gaiola pombaliana', introduced after the 1755 Lisbon earthquake. The 'gaiola' or pomabaliana cage (named after the Marquis of Pombal, a minister who presided over the reconstruction of the city) was a wooden structure independent from the masonry, able to support the floors and the roof in case of earthquake.

The system consists of a set of poles and oak/holm beams. The beams were connected to the wall with a kind of nuts. The tops of the poles were linked together by beams and in the compartments of doors and windows by lintels and rafters (A. França [16]).

After the 1783 Calabria earthquake, the structure of the 'hut' house acquires a more precise and accepted definition with the name of the Bourbon building system or Calabrian hut building according to the actual instructions issued by the Bourbon government in 1784, which represent a real seismic Regulation and provide for an internal timber network for the houses (Barucci [11]). Giovanni Vivenzio [17], was a member of the Commission responsible for the definition of a reconstruction plan. In his 'Historia de' tremuoti' of 1783, he shows the prototype of 
anti-seismic construction employed using three boards drawn by Vincenzo Ferraresi: a woodenframed building structure uprights, transoms and diagonal stiffening (Ceniccola [12]), that according to the thickness of the wall provided for a single or double frame.

In the case of the double frame, in which the two wooden structures were connected by transverse connections, the masonry infilling was placed in such a manner to remain visible. Conversely, the 'instructions for the engineers employed for the Calabria Ulteriore' issued the following year and whose technical solutions belong to the engineers Antonio Winspeare and Francesco La Vega, suggest the use of a completely embedded wooden framing in the wall, to prevent the risk of deterioration of the wood elements. In particular, the houses had to be built with a skeleton of big chestnut or oak uprights, placed in the corners and at a reasonable distance from each other, connected by transverse beams, which were to support the beams of the floors and roofs. This whole timber frame had to be surrounded by a brick wall or small stones bonded with slaked lime.

\subsection{Hut technique and local building practice}

The 'hut' technique, documented in southern Italy since the beginning of the 17th century, was also used in L'Aquila after the catastrophic earthquake in 1703. In his book 'Stabilità sismica dei fabbricati' of 1912, Ruffolo [18] refers to two wooden huts covered in masonry dating back to 1750 , located near Belvedere and behind the Convento di Sant'Amico. Masciari-Genovese [14] also refers to 'hut' models built after 1703.

The anti-seismic house built in Piazza San Bernardino, demolished only after the middle of the 20th century, represent a testimony of the 'hut' system used in L'Aquila after this earthquake. The pictures of its demolition show a framework of uprights, transoms and St. Andrew' crosses, placed inside a stone masonry (D'Antonio [19]).

The earthquake of 2009 has brought to light another example of 'hut' building, still visible in Via Forcella, dated a few years ago after the earthquake of 1703 as a result of the radiocarbon analysis performed on a wooden fragment of the frame ((D'Antonio [19]). It is a three-floor house, with a typical 18th-century construction layout: brick rib vaults on the ground floor, wooden floor on the first floor and embedded (incannucciate) vaults below the wooden trusses roofing.

It is made up of two adjoining rooms and a small subsequent expansion on the street side, now collapsed, and has a structure of wooden uprights, partly squared, simply debarked, connected by squared beams that seem to support the wooden floor. The exterior walls and interior partitions are characterized by the presence of secondary wooden frames.

The case is made of masonry stone blocks and bricks in the same position of the vertical posts so as to form slightly projecting pilasters with respect to the external face of the wall. Inside the wall, there are a series of uprights and wooden elements of $7 \times 5 \mathrm{~cm}$ section. The internal partition between two rooms is in stone masonry on the ground floor, while the upper floors is composed of a wooden trellis infilled with brick masonry to one extremity (Fig. 6).

Other findings resulting from the reconstruction work show how the 'hut' technique was used not only as a system involving the entire wall unit, but also as building approach for individual wall panels after partial interventions of transformation and for the realization of light internal partitions. Such use, also documented in the Sannio area (Ceniccola [12]) can be found in L'Aquila both in standard building and in palace buildings.

In a group of buildings in Via delle Aquile, this construction method was probably used during transformations due to the 18th-century reconstruction (Fig. 7). 

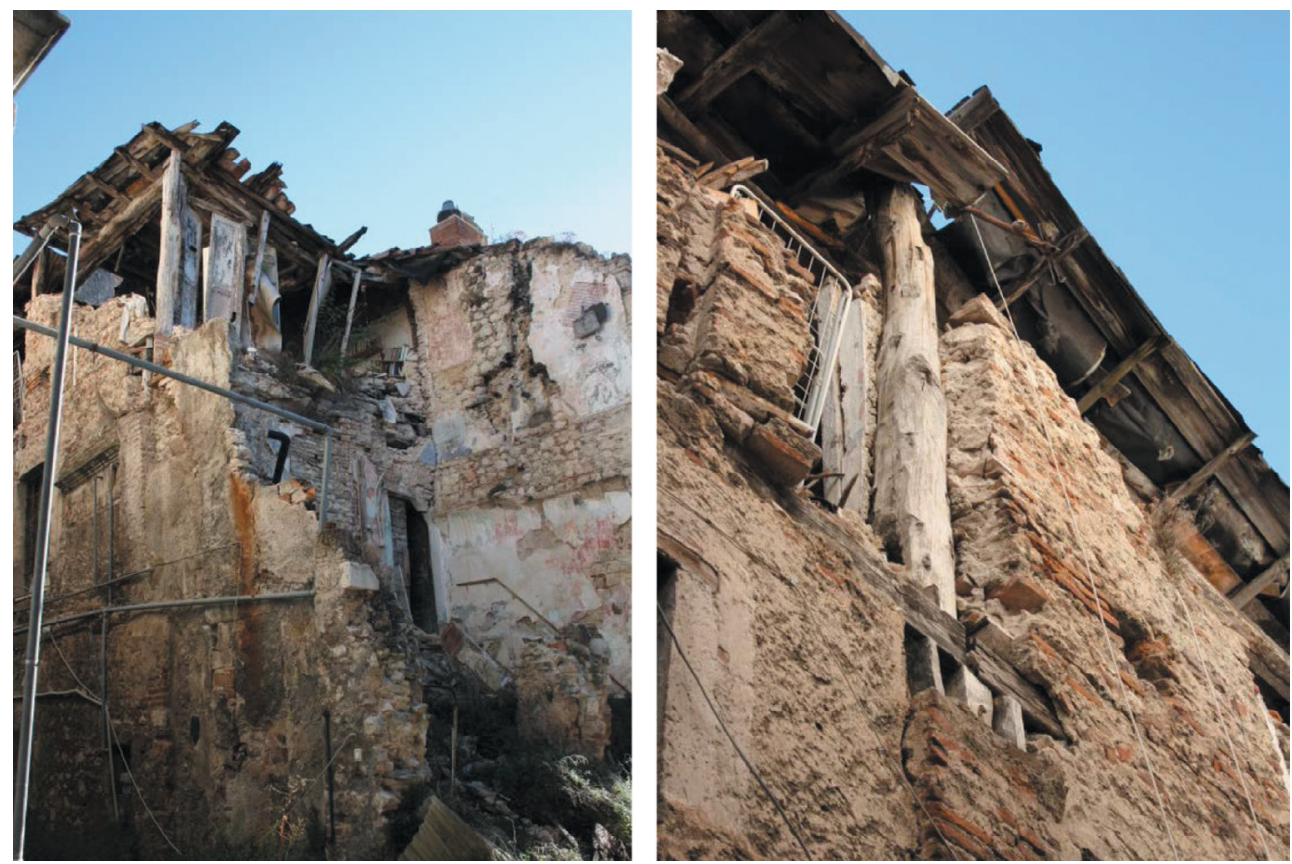

Figure 6: Example of 'hut' building, still visible in Via Forcella, dated a few years ago after the earthquake of 1703 .
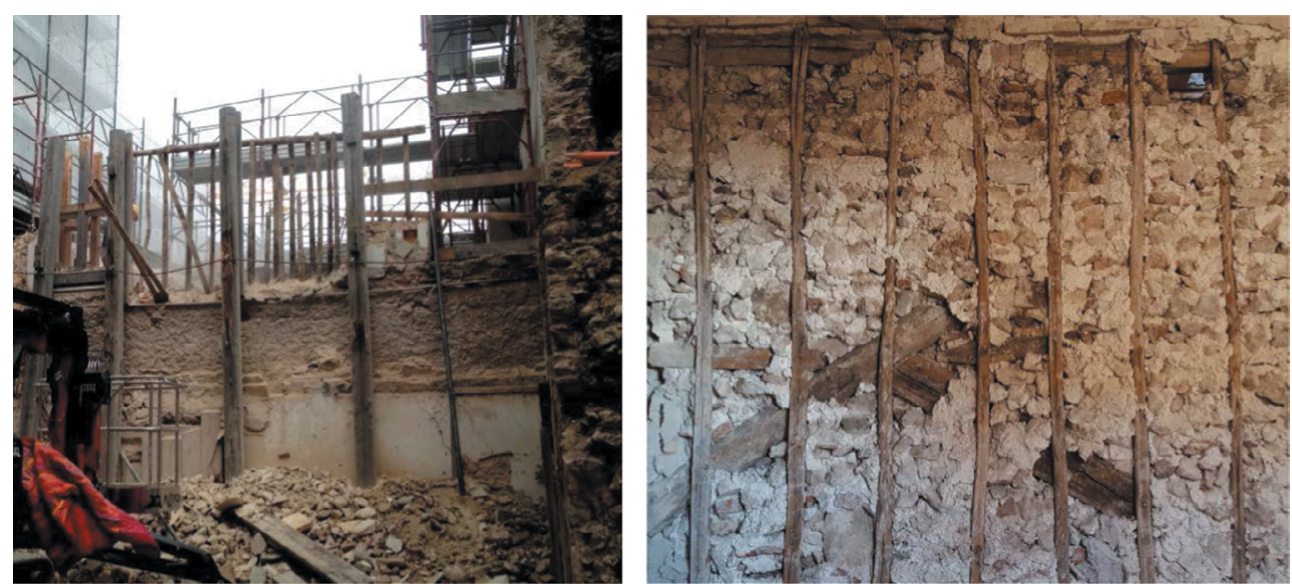

Figure 7: The 'hut' technique in individual wall panels of buildings in Via delle Aquile.

It is a series of wall panels placed on the last of two levels that create the transverse spine walls, which are orthogonal to the main front. The structure of the panels, with a thickness of about $30 \mathrm{~cm}$, is made of three horizontal beams, an upper one, a lower one and an intermediate one, whose section is $15 \times 15 \mathrm{~cm}$, connected by a double sequence of small $8 \times 5$ $\mathrm{cm}$ section uprights, studded on the two exterior sides of the beams and placed at a distance of about $40 \mathrm{~cm}$. In some cases, there is a bracing of diagonal elements arranged in the shape 

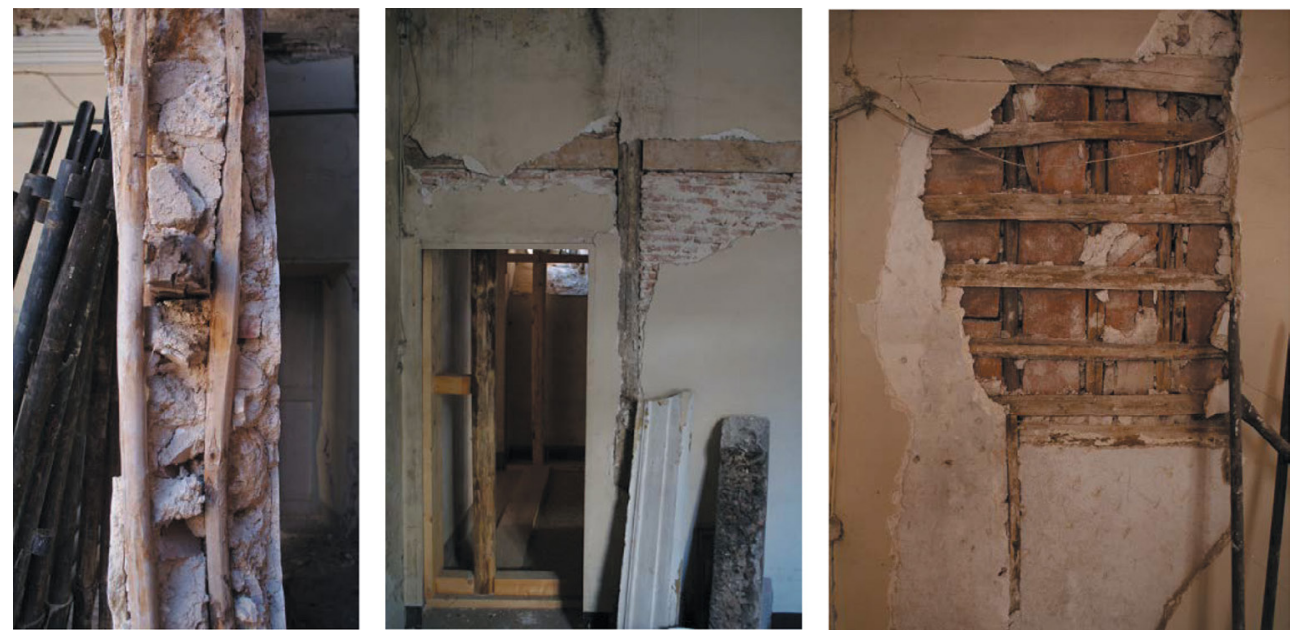

Figure 8: Light partitions attributable to the 'hut' technique in Palazzo Ardinghelli.

of St. Andrew's cross. The resulting meshes are infilled with a stone masonry, made of small blocks with irregular texture, arranged in such a manner that the uprights remain on the external faces of the panels covered with plaster only.

Very similar is the 'hut' masonry found in the 18th-century Palazzo Ardinghelli in Piazza Santa Maria Paganica.

In the phase of 18th-century reconstruction, very common was the use of wooden elements for the realization of framed partition walls useful to the spatial reconfiguration of the indoor settings also in many Aquila palaces. In this case, the wooden trellis represented not only a reinforcement able to increase the stability of thin walls, but also to ensure their better anchoring to the contiguous walls and, last but not least, to ensure the possibility of building non-bearing walls without affecting the underlying vaulted spaces.

In the same Palace, light partitions attributable to the 'hut' technique were found. The first is a partition wall consisting of a frame of uprights and squared-section transoms whose meshes are infilled by a brick masonry as big as a head.

The second, even lighter and weighing on an underlying vault, is formed by a dense lattice of reduced section uprights and transoms, infilled by bricks (Fig. 8).

\section{CONCLUSIONS}

The knowledge of these anti-seismic systems, included in a broader building culture linked to the pre-modern building, and the critical assessment of their role, let us learn from the past about how to preserve the material and construction values of historic buildings according to an approach able to reassess the rules of art even in the choice of intervention procedures not only in terms of repairing the damage but also in terms of improvement of preventive systems of historical buildings.

\section{REFERENCES}

[1] Gavini, I.C., L'architettura in Abruzzo, Costantini Editore: Pescara, Vol. III, pp. 33-44, 1980.

[2] Pierotti, P. \& Ulivieri, D., Culture sismiche locali, Edizioni Plus: Pisa, 2001. 
[3] Cavalieri San Bertolo, N., Istituzioni di Architettura Statica Idraulica, Vittorio Bellini: Firenze, Vol. I, pp. 140-145, 1833.

[4] Alberti, L.B., De re aedificatoria, traduzione di Orlandi G., Edizioni Il Polifilo: Milano, libro III, p. 332, 1966.

[5] Bramanti, A., L'utilizzo di rinforzi lignei nella muratura: ricerche nei siti fortificati medievali della Toscana. Bollettino Ingegneri, 12, pp.3-5, 2002, ISSN 2035-2417.

[6] Curioni, G., L'Arte di fabbricare, Augusto Federico Negro Editore: Torino, pp. 95-96, 1873.

[7] Astrua, G., Manuale pratico del mastro muratore, U. Hoepli: Milano, pp. 156-158, 1893.

[8] Pellegrini, P., L'architettura, edizione critica a cura di Panizza G., Il Polifilo: Milano, 1990.

[9] Valadier, G., L'Architettura pratica dettata nella scuola e cattedra dell'insigne Accademia di San Luca, Società tipografica: Roma, 1828.

[10] Ragucci, L., Principi di Pratica di Architettura, Stamperia del Cattolico: Napoli, pp. 216, 240, 1959.

[11] Barucci, C., La casa antisismica. Prototipi e brevetti, Gangemi Editore: Roma, pp. 13-28, 1990.

[12] Ceniccola, G., Sostenibilità delle strutture intelaiate. La muratura baraccata "alla beneventana". SCIENZA E BENI CULTURALI, XXX, Quale sostenibilità per il restauro?, Edizioni Arcadia Ricerche: Venezia, pp. 669-678, 2014, ISSN 2039-9790.

[13] Paolini, C., La casa antisismica: criteri e soluzioni per la costruzione premoderna. $I L$ SISMA ricordare prevenire progettare, Alinea Editrice: Firenze, pp. 133-142, 2009.

[14] Masciari-Genovese, F., Trattato di costruzioni antisismiche. Preceduto da un corso di sismologia, U. Hoepli: Milano, p. 276, 1915.

[15] Fabrizio, A., I terremoti e i diversi sistemi di costruzioni antisismiche, Stab. Tip. De Martini: Benevento, p. 219, 1933.

[16] França, J.A., Una città dell'illuminismo. La Lisbona del marchese di Pomball, Officina Edizioni: Roma, p. 139, 1972.

[17] Vivenzio, G., Historia e teoria de' tremuoti in generale, ed in particolare di quelli della Calabria e di Messina del 1783, Napoli, 1783.

[18] Ruffolo, F., Stabilità sismica dei fabbricati, Napoli, Italia, p. 104, 1912.

[19] D’Antonio, M., Ita Terraemotus damna impedire. Note sulle tecniche antisismiche storiche in Abruzzo, Carsa Edizioni: Pescara, pp. 185-204, 2013. 